\title{
Cidades Educadoras e a Educação em Humanidades
}

\author{
Ana Paula Scheffer ${ }^{1}$ \\ Patrícia Ketzer ${ }^{2}$
}

\begin{abstract}
RESUMO:
O presente trabalho tem por objetivo investigar como o movimento Cidades Educadoras pode contribuir para a educação em humanidades, a qual vem sendo, a cada reforma educacional, mais escamoteada. Pretende-se demonstrar a possibilidade da educação em humanidades nos espaços não formais $\mathrm{e}$ informais de ensino, como é o caso da cidade. Trata-se de uma pesquisa bibliográfica na qual serão abordados, na primeira parte o conceito de cidade e democracia. Posteriormente, apresenta-se uma análise da importância da educação em humanidades no contexto democrático. E, por fim, identifica-se as contribuições do movimento Cidades Educadoras para a educação em humanidades.
\end{abstract}

Palavras-chave: Cidades Educadoras. Educação em Humanidades. Democracia.

\begin{abstract}
:
This work aims to investigate how the Educating Cities movement (Movimento Cidades Educadoras) can contribute to education in Humanities, which has been, with each educational reform, more concealed. It is intended to demonstrate the possibility of education in the Humanities in non-formal and informal teaching spaces, as is the case of the city. This is a bibliographic research in which the concepts of city and democracy will be addressed in the first part. Subsequently, an analysis of the importance of humanities education in the democratic context is presented. And, finally, as a conclusion, we identify the contributions of the Educating Cities movement to humanities education.
\end{abstract}

Keywords: Educating Cities. Humanities Education. Democracy.

\footnotetext{
${ }^{1}$ Arquiteta e Urbanista, graduada pela Universidade de Passo Fundo - UPF (2015). Participou como bolsista de Iniciação Científica PIBIC/UPF na área de Análise e Diagnóstico da Ecoeficiência na UPF (2013/2015), atuou como Agente de Orientação em Design (AOD) pelo Sebrae-RS (2015).

${ }^{2}$ Possui graduação (2008) e mestrado (2010) em Filosofia pela Universidade Federal de Santa Maria e doutorado em Filosofia pela Pontifícia Universidade Católica do Rio Grande do Sul (2015). Atualmente é professor adjunto II da Universidade de Passo Fundo, onde coordena a especialização em Ciências Sociais e o Projeto de Extensão em Economia Solidária e Equidade de Gênero.
} 


\section{Introdução}

Segundo a Carta Cidades Educadoras (AICE, 2013), o grande desafio do século XXI é investir na educação de cada indivíduo, de modo que esse seja cada vez mais capaz de exprimir, afirmar e desenvolver o seu próprio potencial humano. Para tal, além de investir numa educação formal, é indispensável contemplar uma proposta integradora que inclua também uma educação não formal e informal, na qual a cidade seja também uma escola: "Na Cidade Educadora, as diferentes políticas, espaços, tempos e atores são compreendidos como agentes pedagógicos, capazes de apoiar o desenvolvimento de todo potencial humano" (CIDADES EDUCADORAS, 2018).

A capacidade de a cidade ser um meio para educar, vem sendo constantemente trabalhada através do movimento Cidades Educadoras, cujos seus integrantes podem divulgar experiências, fundamentar os seus objetivos e construir um mundo de sabedoria a partir de cada pequena troca, ação ou relação nas cidades. Em termos de educação para as humanidades, verifica-se um grande potencial de discernimento, uma vez que a cidade pode ser considerada um símbolo das relações sociais.

Com base no exposto, definiu-se como objetivo do trabalho em questão, investigar como o movimento Cidades Educadoras vem contribuindo para uma educação em humanidades, estruturou-se o trabalho em três partes, a saber: em um primeiro momento, através de uma pesquisa bibliográfica, é abordada a relação entre Cidades Educadoras e a democracia; em segundo, optou-se por lançar mão da obra Sem fins lucrativos: por que a democracia precisa das humanidades (NUSSBAUM, 2015), da filósofa Martha Nussbaum, como instrumento de reflexão sobre o papel e a importância da educação em humanidades no contexto da democracia. Por conseguinte, essas duas temáticas são articuladas, a fim de 
identificar como o movimento Cidades Educadoras pode contribuir para a educação em humanidades.

\section{A relação imanente entre Cidade Educadora e a democracia}

A Organização das Nações Unidas (ONU, 2018) constata que em 2018 mais de 55\% da população mundial morava em cidades, com previsão de chegar aos $68 \%$ de habitantes vivendo em áreas urbanas até 2050. Mas, o que poder-se-ia definir como cidade? Um lugar, um espaço, uma aglomeração?

Segundo Vasconcelos $(2015$, p.2) a definição de cidade aparece pela primeira vez no livro A Ideologia Alemã (MARX; ENGELS, 1984) como "a realidade da concentração da população, dos instrumentos da produção, do capital, dos prazeres, das necessidades [...]". Rolnik (1988, p.13), em seu livro $O$ que é Cidade, trabalha o conceito através de uma metáfora: "a cidade é antes de mais nada um ímã, antes mesmo de se tornar local permanente

de trabalho e moradia".

Cidade romana, muçulmana, medieval, renascentista (ABIKO et al., 1995)... dentre tantos "arquétipos" de cidade, cabe a esse artigo destacar às Cidades-Estados da Grécia, mãe da democracia a qual partia do pressuposto de que todos eram iguais perante a lei e tinham o mesmo direito à palavra. Conceitualmente a democracia grega caracterizava-se por três valores: igualdade, liberdade e participação (ARANHA, 2013) ${ }^{3}$.

Observa-se que tais características parecem estar estritamente vinculadas a ideia de Cidades Educadoras, podendo ser definida como "aquela que, para além de suas funções tradicionais, reconhece, promove e exerce um papel educador na vida dos sujeitos, assumindo como desafio permanente a formação integral de seus habitantes" (CIDADES EDUCADORAS, 2018).

\footnotetext{
${ }^{3}$ É válido ressaltar quanto ao fato de a democracia ateniense ser marcada por fortes elementos de exclusão, na medida que ela não se estendia a toda a população (NETO, 1997, p.288). No entanto, é notável a criação desse modelo de governo em que a política aristocrática é substituída pela participação dos cidadãos (ARANHA, 2013), regime que, futuramente, influenciaria a história das cidades (e humanidades).
} 
Para uma cidade servir de exemplo e ser educadora é indispensável que o contexto urbano seja estruturado de modo que a igualdade, liberdade e participação sejam valores fundantes. A base para que os indivíduos que se relacionam com o espaço urbano possam usufruir de uma relação dialógica de aprendizado, cultivo de si e respeito ao outro e ao meio.

Nunca é demais salientar a importância insubstituível que a educação tem em uma sociedade. É a referência ao respeito e à autonomia. Nussbaum (2015, p.10) nos lembra que "a educação não é útil apenas para a cidadania. Ela prepara as pessoas para o trabalho e, o que é fundamental, para uma vida que tenha sentido".

Diante desse importante papel, insere-se a ideia de que os seres humanos são seres inacabados e não podem realizar-se senão ao preço de uma aprendizagem constante, ou seja, a educação não pode ter um conceito estático envolto de uma sala de aula, mas sim, deve possuir seu lugar em todas as idades da vida e na multiplicidade das situações e das circunstâncias da existência (FAURE, E. Op. cit. p. 225 apud WERTHEIN, J.; CUNHA, C. 2005, p.14).

Ao passo que a cidade também é definida por uma constante construção diretamente vinculada ao ser humano, cujas reações e relações são dificilmente individualizadas de modo analítico; estão compreendidas na estrutura dos fatos urbanos, não havendo transformação urbana que não signifique também uma transformação da vida de seus habitantes (MONTANER, 2014).

É nesse sentido que a verdadeira natureza global da educação é retomada, ganhando força e voz, no $1^{\circ}$ Congresso Internacional das Cidades Educadoras (BARCELONA, 1990), reunindo em uma carta os princípios essenciais ao impulso educador da cidade, apresentando como objetivo permanente: "aprender, trocar, partilhar e, por consequência, enriquecer a vida dos seus habitantes" (AICE, 2013).

No que diz respeito a esses dois termos - Cidades Educadoras e democracia - constata-se que a aproximação é imanente à medida que retomamos os ideais de igualdade, liberdade e participação, vinculando-os à 
compreensão de que dificilmente se promoverá o convívio harmônico no planeta, sem que cada cidadão tenha consciência do seu papel responsável e participativo na promoção de um mundo mais justo e fraterno. Nesses conceitos, a concepção de educação em humanidades surge de modo intrínseco, como um elemento ativo, que reage promovendo exercícios de cidadania. A respeito especificamente da relação entre democracia e humanidades, o capítulo a seguir é fundamentado.

\section{Por que a democracia precisa das humanidades}

Nussbaum (2015), em seu livro Sem Fins Lucrativos: Por que a democracia precisa das humanidades, alerta quanto ao fato de estarmos presenciando uma espécie de crise silenciosa:

uma crise de enormes proporções e grave significação global. Não, não me refiro à crise econômica global que começou em 2008. Pelo menos naquela época, todas sabiam que estavam diante de uma crise (NUSSBAUM, 2015, p.3).

Não se pode afirmar quanto às origens que convergem para uma crise nas humanidades, talvez seja até mesmo difícil constatar se essa crise é fruto do momento atual ou muito antes já se estruturava nos jogos econômicos, cujo lucro parecia e parece justificar, muitas vezes, a submissão e a amnésia das humanidades.

A realidade, é que os fatos apresentados por Nussbaum (2015), se encaminham para comprovar o quanto a humanidade anda esquecendo das humanidades: "tanto no ensino fundamental e médio como no ensino superior, as humanidades e as artes estão sendo eliminadas em quase todos os países do mundo" (NUSSBAUM, 2015, p.4).

No Brasil, um exemplo contemporâneo ao processo, pode ser citado por meio da Base Nacional Curricular Comum do Ensino Médio (2018), uma vez que, ao se manter apenas as disciplinas de português e matemática 
como obrigatórias, se estabelece uma espécie de hierarquia de importância, que segundo o Centro de Referências em Educação Integral (2018), dificulta uma visão interdisciplinar e contextualizada do mundo, podendo levar à formação de uma geração de jovens pouco qualificados, acríticos, manipuláveis, incapazes de criar e condenados aos trabalhos mais simples e entediantes.

Nesse sentido, o alerta quanto a crise silenciosa, se faz imprescindível como ponto de partida para argumentar a respeito da importância das humanidades a fim de se evitar que humanos sejam produzidos em série. Para tanto, é fundamental identificarmos o que vem significando e, o que deveria significar, um país progredir. Nussbaum (2015) comenta que para alguns países, em determinado ponto de vista significa aumentar o PIB per capita. De acordo com esse modelo de desenvolvimento, o objetivo deve ser o desenvolvimento econômico:

Esqueça igualdade social, esqueça os pré-requisitos necessários de democracia estável, esqueça a qualidade das relações raciais e de gênero, esqueça o aperfeiçoamento de outros aspectos da qualidade de vida do ser humano que não estejam completamente ligados ao crescimento econômico (estudos empíricos já demonstraram que não existe uma correlação significativa entre liberdade política, saúde e educação, de um lado, e crescimento, de outro) (NUSSBAUM, 2015. p.14).

No que diz respeito ao que deveria significar a palavra desenvolvimento, a própria Nussbaum na citação anterior, responde intrinsecamente, ao que exatamente deveríamos atentar. Dentre inúmeras questões, a autora enfatiza um tema em especial: a educação. Para ela, é através do conhecimento, que conseguimos interagir, nos colocar no lugar do outro (empatia) e ter compaixão. É interagindo e não excluindo, que conseguimos capacitar o ser humano a ser mais receptivo e ativo quanto as diferentes realidades que compõem o mundo. 
Nussbaum considera ainda a pedagogia socrática como o método que deveria inspirar professores a compreender que educar não é expelir conteúdos de maneira ordenada, mas sim, instigar o aluno a ponto de fazer com que ele mesmo desenvolva um raciocínio lógico, fundamentado no diálogo e na visão de uma contínua construção de ideias, lembrando Tagore (apud NUSSBAUM, 2015, p. 47): "Nossa mente não alcança a verdadeira liberdade adquirindo matérias de conhecimento e apoderando-se das ideias dos outros, mas formando seus próprios critérios de julgamento e produzindo suas próprias ideias."

A importância das humanidades é apresentada à medida que se compreende que não só de conhecimento factual vive o ser humano. Para Nussbaum (2015, p. 96) o desenvolvimento da compreensão deve ser incentivado através de uma educação participativa que estimula e aprimora a capacidade de perceber o mundo através de outra pessoa. É especialmente por essa razão que as disciplinas fundamentadas na nomenclatura "humanidades" devem ser incentivadas. Exemplos como: literatura, filosofia, artes visuais, teatro, dança e tudo o que incentive tal exercício, deve receber o devido investimento, a fim de se promover um mundo mais igualitário, em conjunto com o pensamento crítico e a criatividade.

Para Nussbaum (2015), a educação não acontece somente na escola, sendo que a maioria das características que representam o seu foco de estudo deve ser estimulada na família, salientando também quanto a cultura de grupo que nos cerca e a cultura mais ampla das normas sociais e das instituições políticas, que desempenham um importante papel. É nesse contexto, que o capítulo a seguir apresenta uma abordagem a respeito de como o movimento Cidades Educadoras pode contribuir para uma educação em humanidades.

\section{Cidades Educadoras e a Educação para as Humanidades}

Segundo Werthein e Cunha (2005, p.15) a transformação de uma cidade em educadora possui implicações incomensuráveis para a educação, uma vez que a instituição escolar não será mais o único local de 
aprendizagem, mas toda a sociedade. Nesse contexto, Liizop trabalha com a ideia de educação descentralizada, argumentando:

Em vez de se delegar os poderes a uma estrutura única verticalmente hierarquizada e constituindo um corpo distinto no interior da sociedade, são todos os grupos, associações, sindicatos, coletividades locais, corpos intermediários, que devem encarregar-se, pela sua parte, de uma responsabilidade educativa (LIIZOP apud WERTHEIN.; CUNHA, 2005, p.15).

Segundo Freire (1992), a cidade converte-se em Cidade Educadora a partir da necessidade de educar, de aprender, de imaginar; sendo educadora, a cidade é, por sua vez, educada. Diante dessa perspectiva, é inegável que, ao trabalhar diretamente com o ser humano e suas relações no meio urbano, a educação para as humanidades se potencializa, estabelecendo um vínculo dialógico entre o ser e a cidade.

A fim de exemplificar um pouco mais dessa relação, a seguir são apresentadas algumas experiências do movimento Cidades Educadoras que contribuem para uma educação plural e possuem em sua essência um viés para as humanidades. Para tanto, o artigo em questão lançou mão dos princípios de uma Cidade Educadora (IPCCIC, 2019, p.186) identificandoos em aplicações práticas. Para localizar as ações, efetivou-se uma busca selecionando-se experiências cadastradas no banco de experiências da Associação Internacional de Cidades Educadoras - AICE (página virtual que compartilha as ações promovidas por meio do movimento).

Na experiência intitulada Red de Innovación Educativa, evidencia-se o princípio de "trabalhar a escola como espaço comunitário". A iniciativa possui por objetivo adaptar a educação às novas necessidades sociais, promovendo a inclusão social dos cidadãos. A rede se configura como um grupo de trabalho interdisciplinar (administração pública, escolas, familiares e empresas), que fomentam ideias e promovem iniciativas voltadas à 
integração de tecnologias nos processos educacionais (VILADECANS, 2013).

Com o intuito de "valorizar o aprendizado vivencial", um dos princípios de uma Cidade Educadora, apresenta-se a experiência intitulada Ciudadanos Como Vos, a qual visa reforçar a cultura cidadã, estabelecendo uma narrativa de reconhecimento mútuo na cidade através da visibilidade positiva de personagens, histórias e dados que contribuem para melhorar a convivência na cidade (CIDEU, 2018).

"Trabalhar a cidade como um grande espaço educador" é um dos princípios que pode ser evidenciado por meio da experiência Clases a pie de calle, cujo movimento materializa uma inovadora aliança entre os serviços municipais de educação e o comércio de proximidade, a fim de oferecer espaços de formação em temas propostos pelos cidadãos (AICE, 2019).

A experiência intitulada como Moradores - A Humanidade do Patrimônio desenvolve o princípio de "aprender na cidade, com a cidade e com as pessoas". A iniciativa visa percorrer cidades fotografando e entrevistando pessoas, posteriormente, ocupando o espaço público com exposições que convidam o passante a conhecer a cidade para muito além de seu patrimônio palpável (GARCIA, 2018).

Diante do exposto, é possível inferir que todas as experiências elencadas possuem, também, o papel de priorizar a formação de valores (outro princípio). Valores os quais são aprendidos e ensinados pelo contexto urbano, que incentivam o cidadão a sentir-se parte do espaço urbano, a reconhecer o outro (por meio de sua cultura, ensinamentos e relacionamentos). Propriedades essenciais para o respeito e a igualdade dissertados por Nussbaum, bem como para a promoção de um espaço democrático, que como vimos, é potencializado pelo vínculo com a educação em humanidades.

Por fim, reconhece-se que o movimento Cidades Educadoras pode contribuir para a educação em humanidades por meio do seu incentivo à educação no espaço urbano. Ação esta que está diretamente ligada às contribuições do movimento por meio do comprometimento e promoção de 
experiências, publicações, divulgações e plano de ações, que visam potencializar o papel de transformação do cidadão.

\section{Conclusão}

Perante às explanações apresentadas nesse trabalho, pode-se observar que o movimento Cidades Educadoras vem dialogando com a seguinte discussão: O que a cidade tem a nos ensinar? Observa-se então, que assim como a arquitetura, a cidade também “deve assumir sua dimensão pública e utilizar a metáfora, o símbolo e a história para se conectar com as pessoas" (MONTANER, 2014, p.152).

Diante dessa conexão, o presente artigo teve por objetivo identificar como o movimento Cidades Educadoras pode contribuir para a educação em humanidades. Para tal, foram apresentados alguns conceitos relativos à Cidade Educadora e democracia a fim de compreender como esses termos se relacionam.

Em um segundo momento, Martha Nussbaum é apresentada através do livro Sem Fins Lucrativos (2015), com o intuito de justificar a importância das humanidades para democracia, uma vez que elas fazem parte do cerne do desenvolvimento humano e são a base primordial para se estabelecer virtuosas relações sociais.

Apesar da ênfase de Nussbaum estar relacionada à educação escolar e familiar, pode-se perceber que seus conceitos perpassam as barreiras físicas de qualquer espaço, e permeiam sempre uma educação que respeite o ser humano, que por sua vez saiba se posicionar criticamente, com educação e respeito.

Em um terceiro momento, objetivou-se integrar essas duas perspectivas (cidade e humanidades) a fim de demonstrar o potencial de contribuição para a educação em humanidades que a urbe possui, por meio das Cidades Educadoras. Identificou-se, assim, uma forte relação entre Nussbaum e o movimento, uma vez que o conceito de cidades educadoras faz uso dos mesmos pressupostos encontrados no discurso da filósofa que visam uma extensão à educação, utilizando as cidades como sala, 
fortalecendo o ambiente como espaço de troca e experiências que promovam a integração cidadã.

É de suma importância salientar que, apesar deste trabalho ter por intuito demonstrar bons exemplos, a educação em humanidades corre riscos, ainda mais nos tempos atuais cujo investimento nas áreas de humanidades é visto como superficial:

A argumentação que fiz até agora pretende ser um chamado à ação. Caso se chegue à conclusão de que as coisas estão menos ruins do que acredito que estejam, isso não é motivo para respirar aliviado; devemos fazer exatamente o que faríamos se acreditássemos que as coisas estão bem desanimadoras. Devemos redobrar nosso compromisso com os elementos da educação que mantêm a vitalidade da democracia (NUSSBAUM, 2015, p.122).

Ou seja, a conscientização de educadores, governantes e da sociedade de modo geral, a fim de reconhecer a importância e a implicação que as humanidades possuem na formação humana, se faz indispensável. Caso contrário, já dizia Nussbaum, a democracia estará fadada ao fracasso, uma vez que ela se baseia no respeito e na consideração, e esses, por sua vez se baseiam na capacidade de perceber os outros como seres humanos, não como meros objetos. Eis que se compreende a necessidade das humanidades.

\section{Referências}

ABIKO, A. K.; ALMEIDA, M. A. P. de; BARREIROS, M. A. F. Urbanismo: história e desenvolvimento. Escola politécnica da Universidade de São Paulo - Departamento de Engenharia e construção civil, 1995. Disponível em: http://reverbe.net.cidades/wp-content/uploads/2011/08/urbanismohistoriaedesenvolvimento. Acesso em: 27 nov. 2018. 
AICE - ASSOCIAÇÃO INTERNACIONAL DE CIDADES EDUCADORAS. Carta Cidades Educadoras. AICE. 2004. Disponível em: http://www.edcities.org/wp-content/uploads/2013/10/Carta-Portugues.pdf. Acesso em 12 nov. 2018.

AICE. Ciudades Educadoras, experiência destacada: Clases a pie de calle. 2019. Disponível em: https://www.edcities.org/wpcontent/uploads/2020/01/ESP_Experiencia destacada-33_Andong-.pdf. Acesso em: 25 abri. 2020.

ARANHA, M. L. A. A Democracia. Filosofia. Uno Internacional. 2013. Disponível em: https://ola.coop.br/articles/oceb/0042/9955/pdf.pdf. Acesso em: 12 nov. 2018.

BRASIL. BNCC - Base Nacional Comum Curricular. Ensino Médio. Ministério da Educação, 2018.

IPCCIC - Instituto Paulista de Cidades Criativas e Identidades Culturais. Seis passos para a cidade bumana. Barueri, São Paulo: Estação das Letras e Cores, 2019.

CENTRO DE REFERÊNCIAS EM EDUCAÇÃO INTEGRAL. Entenda as divergências sobre Reforma do Ensino Médio e BNCC que fizeram Callegari renunciar. Disponível em: https://educacaointegral.org.br/reportagens/entenda-asdivergencias-sobre-reforma-ensino-medio-bncc-que-fizeram-callegarirenunciar/. Acesso em: 11 nov. 2018.

CIDADES EDUCADORAS. Conceito. 2018. Disponível em: https://cidadeseducadoras.org.br/conceito/. Acesso em: 12 nov. 2018.

CIDEU. Ciudadanos Como Vos. 2018. Disponível em: https://www.cideu.org/proyecto/ciudadanos-como-vos/. Acesso em: 25 de abril de 2020 . 
FREIRE, P. II Congresso Internacional de Cidades educadoras. Gotenburgo, Suécia, p. 25-27, novembro, 1992.

GARCIA, C. Cidades Educadoras. Projeto coleta histórias de moradores para valorizar o patrimônio imaterial das cidades. 2018. Disponível em: https://cidadeseducadoras.org.br/reportagens/projeto-coleta-historias-demoradores-para-valorizar-patrimonio-imaterial-das-cidades/. Acesso em 11 nov. 2018.

MARX, K.; ENGELS, F. A Ideologia Alemã. São Paulo: Moraes, 1984.

MONTANER, J. M. Depois do Movimento Moderno. Arquitetura da segunda metade do século XX. São Paulo: Editorial Gustavo Gili, 2014.

NETO, A. C. Democracia: Velhas e Novas Controvérsias. Estudos de Psicologia. v.2. p. 287-312. 1997.

NUSSBAUM, M. Sem Fins Lucrativos: Por que a democracia precisa das humanidades. São Paulo: Wmf Martins Fontes, 2015.

ONU - ORGANIZAÇÃO DAS NAÇÕES UNIDAS. World Urbanization Prospects: The 2018 Revision. 2018. Disponível em: https://esa.un.org/unpd/wup/Publications/Files/WUP2018-KeyFacts.pdf. Acesso em: 09 ago. 2018.

ROLNIK, R. O que é a cidade. São Paulo: Brasiliense, 1988.

VASCONCELOS. As Metamorfoses do Conceito de Cidade. Mercator, Fortaleza, v. 14, n. 4, Número Especial, p. 17-23, dez. 2015.

VILADECANS. Xarxa D'innovació Educativa. 2013. Disponível em: http://xieviladecans.cat/. Acesso em: 25 abri. 2020. 
WERTHEIN, J.; CUNHA, C. Fundamentos da Nova Educaşão. Brasilia: UNESCO, 2005.

Submetido em: 05/02/2020

Aceito em: 23/06/2020

Publicado em: $30 / 08 / 2020$ 